\title{
Does the Future of Mobility Depend on Public Transportation?
}

\author{
Kari Watkins \\ Georgia Institute of Technology
}

We've all seen the headlines. "Will self-driving cars, taxis make mass transit obsolete?" (Davidson 2017) and "What happens if Uber or Lyft outcompetes public transit?" (Sen 2017) or even "Department Of Transportation Says The Future Of Transit Looks Pretty Bleak" (Griggs 2015). We are entering the next great revolution in how people move about in cities. But does the future of transportation mean the end of transit?

\section{What is the definition of public transportation?}

To address the question of the future of public transportation, we must begin with what public transportation is. Leading agencies and experts in the field define public transportation systems today by their basic forms, operation, and design. However, some definitions hint at how we must think of public transportation as our systems move into the future. The American Public Transportation Association (APTA) defines public transportation as "transportation by a conveyance that provides regular and continuing general or special transportation to the public" (Neff 2017). Vukan Vuchic defines urban public transportation as "Transport system(s) for intraurban or intraregional travel available for use by any person who pays the established fare" (Vuchic 2007). He categorizes public transportation as consisting of both transit and paratransit. While transit is noted as having "fixed routes and schedules, such as bus, trolleybus, and rail services," paratransit includes "modes of passenger transportation consisting of small or medium capacity highway vehicles offering service adjustable in various degrees to individual users' desires." Wikibooks' Fundamentals of Transportation/Transit defines public transit as "a mode of transportation that involves moving persons from one place to another using a common form of conveyance, allowing multiple persons to share a common vehicle while traveling" (Wikibooks 2017).

While the APTA and Vuchic definitions are correct technically and form the basis of how we operate and design public transportation systems today, the Wikibooks definition hints at

(C) 2018 Kari Watkins

http//dx.doi.org/10.5038/2375-0901.21.1.6

ISSN: 1077-291X | Licenced under Creative Commons License Attribution - Noncommercial 4.0

The Journal of Public Transportation is published by the Center for Urban Transportation Research at the University of South Florida 
how we must think of public transportation as we move forward. Public transportation is simply collective mobility - a form of transportation that is shared among multiple users. Therein lies the key to why public transportation matters and will always matter. Given the available space in urban environments, we must travel collectively to have an effective urban transportation system.

\section{Why must we travel collectively?}

To communicate clearly the idea of how much space transportation modes use, an image that has circulated for years that originated with the City of Muenster in Germany shows space requirements for travel by car, bus, or bicycle. The underlying theme of this image is that we simply cannot take up the space required for individual travel by operating in fourto six-passenger vehicles with only one person in the car. The spatial, environmental, safety, and equity impacts of a transportation system designed around the single-occupant-vehicle mode are not efficient or sustainable. This has always been public transportation's theme song. Transit providers enable people to travel collectively, thus saving them time, money, and stress, and reducing system-wide emissions.

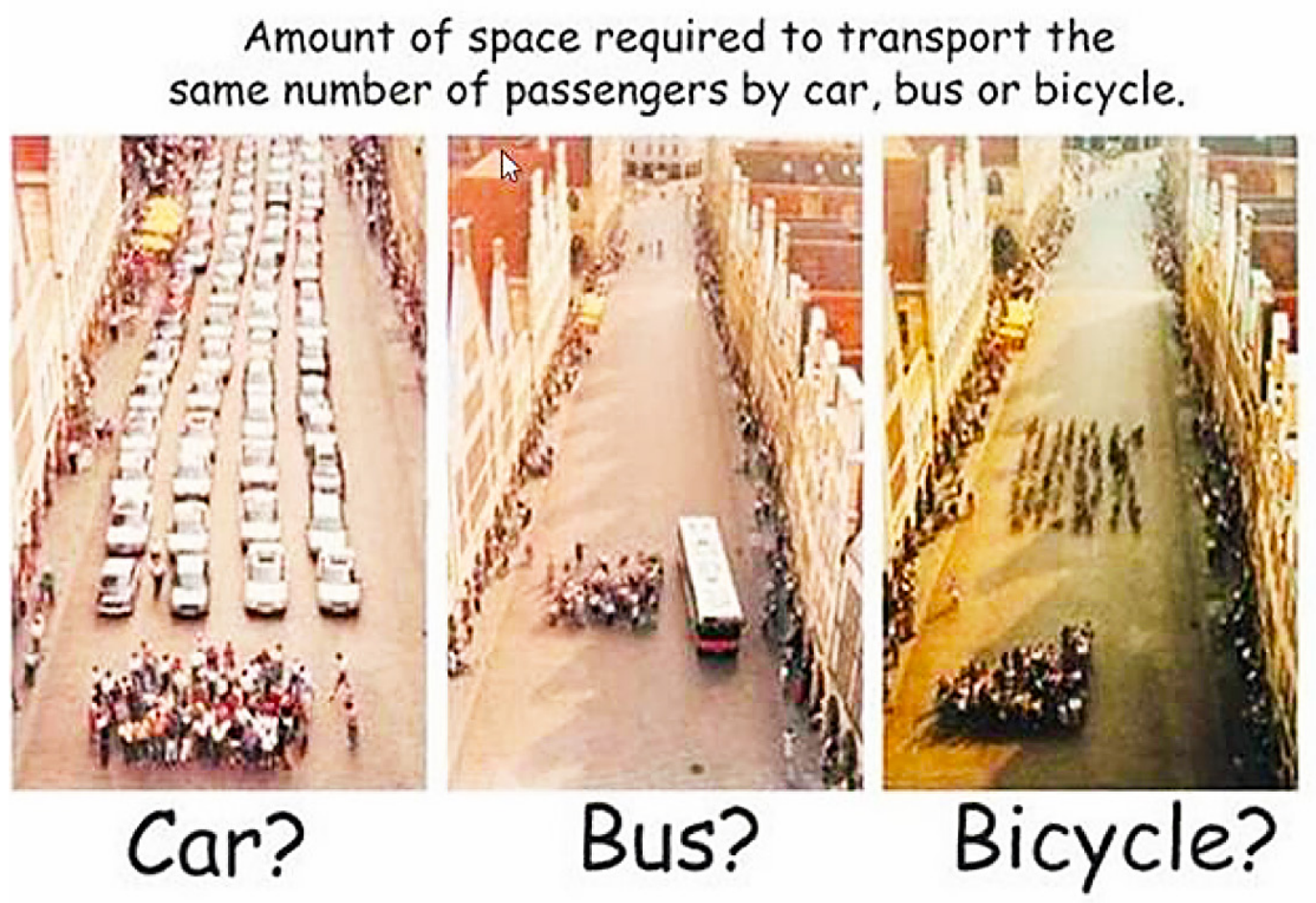

FIGURE 1.

City of Muenster Image (Richard 2009)

In the last few years, the transportation industry has been distracted by two themes: transportation network companies and autonomous vehicles. Transportation network companies (TNCs) such as Lyft, Gett, and Uber have used technology to make taxi-type services (essentially a form of paratransit) easier to use for those with access to technology and without the need for vehicles with ADA accommodations. Although limited research has been done to understand the relationships to date, some in the industry fear that TNCs have depleted and will continue to deplete transit ridership (Polzin 2016). The early forms 
of highly automated vehicles (AVs), which have been anticipated for years, allow drivers to give up control of their vehicles and use travel time for other activities. Both of these contemporary transportation concepts allow car drivers to overcome the biggest individual negative aspect to their mode-the stress and time involved in paying attention to the road ahead-something that has long been used to attract new riders to transit.

However, while TNC and AV concepts provide alternatives for some public transportation riders, they do not address the system implications of private transportation. As eloquently illustrated by Jon Orcutt at TransitCenter, both TNCs and AVs in their current forms do nothing to address the space issue (Orcutt 2016). Although TNCs offer shared ride services, including LyftLine and UberPool, the number of carpool trips is far less than their typical non-shared services, and drivers are typically not en route to their own destination other than serving a customer. Therefore, TNCs create the same number of trips as singleoccupant vehicles and some research has indicated they may even create more vehicle miles traveled (VMT) due to the dead-heading between paid trips (San Francisco County Transportation Authority 2017). Likewise, autonomous vehicles in their current form are not encouraging shared ownership, let alone shared use. Most theories to date show an increase in VMT that will likely negate any increases in efficiencies and cause rising congestion levels. In the heaven-or-hell scenarios of a driverless vehicle future, current (lack of) policy points us in the worst possible direction (Chase 2014).

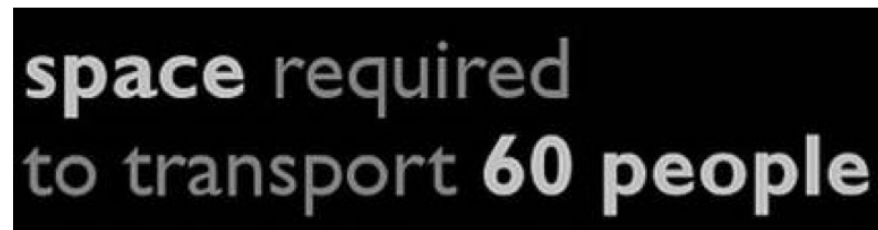

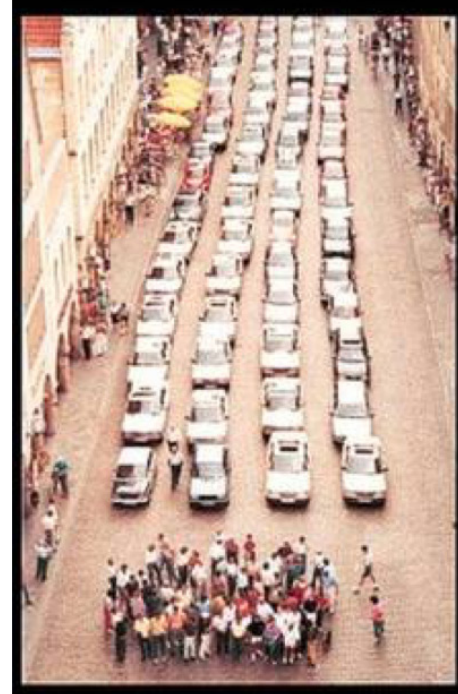

car

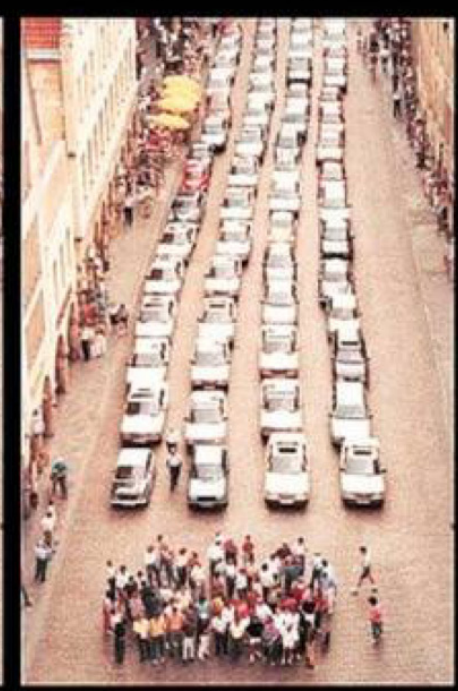

uber

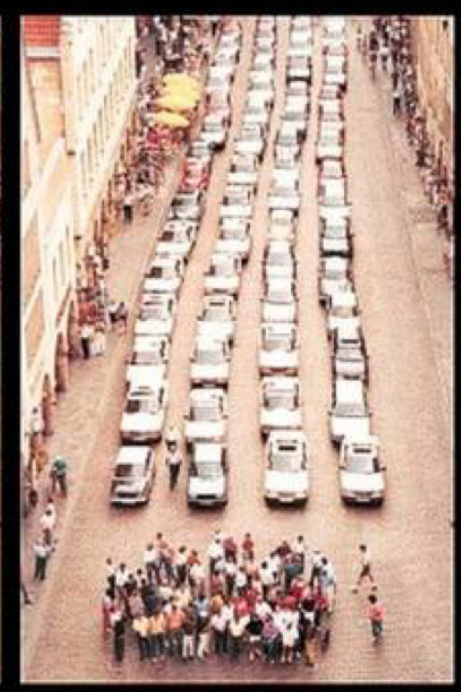

autonomous car

FIGURE 2.

Updated Image by Jon Orcutt 


\section{How can we ensure a livable and effective future transportation system?}

To create a livable and effective future transportation system, the transit industry must act on four principles.

1. If travel is a utility, then mobility must be a service. The concept of Mobility as a Service (MaaS) combines private and public transportation services seamlessly to enable travel without personal vehicle ownership. MaaS uses public transportation as the backbone of the service. When the local transit agency cannot serve a trip, the user can access any number of alternative mobility providers such as TNCs, bikeshare, and paratransit/taxi. MaaS is similar to TNCs in that it uses apps to plan a trip, locate or hail a vehicle, and pay for the trip all in one place. To date, both Sweden and Finland have implemented MaaS successfully and we can look to their efforts for guidance (UbiGo 2017, MaaS Global 2017).

This kind of seamless travel with collective transportation as the backbone must be the basis for transportation into the future. Such services use the best of high-capacity public transportation for the bulk of travel distances, with localized services for short trips and first mile/last mile connectivity. This enables people to travel collectively when it makes the system more efficient, but addresses individual needs to get all the way from origin to destination. The name behind MaaS is perhaps the biggest key. Mobility must be transformed to be perceived as a high-quality utility. The connection from one service to another must be efficient and pleasant, with good information and minimal delay.

2. Spatial priority must be given to collective transportation modes. When transit vehicles with larger capacities and shared ride vehicles that are utilizing space more efficiently through carpooling are mixed in with general traffic, there is no incentive for people to choose a shared vehicle situation. The transportation network must be designed to give exclusive right-of-way corridors to collective transportation modes. High-occupancy vehicle (HOV) lanes, transit lanes, and priority corridors must become the norm in the transportation system. Individuals who are using space efficiently must receive priority over those who congest the network.

Heavy rail modes have long enjoyed preference over bus travel due to exclusive rights-ofway that third-rail technology requires, but rubber on pavement is as efficient as steel on steel. Bus rapid transit projects have shown that rubber-tired vehicles can attract riders in significant numbers and achieve high reliability and low travel times if given priority over general traffic. The lesson here is that transit becomes effective in the priority over use of space and unimpeded travel.

As driverless vehicles become the norm, this spatial allocation for collective modes will become much more important. Imagine for a minute that I own a driverless vehicle. To avoid parking in the pricey high-density area where I work, I have my vehicle take me to work, return home to park, return to get me later in the day, and drive me back home. Where two single-occupant trips previously existed, a future transportation system may have not only those two trips, but also an additional two zero-occupant trips. If these trips occurred with a shared fleet, two trips rather than four would remain and we would 
eliminate the parking required today. However, there is still no incentive for travelers to utilize the space within the vehicle with additional passengers or to travel in a smaller vehicle, unless such vehicles receive priority. Transportation services must prioritize vehicles that are no bigger than the space needed for immediate transportation, such as a standard car with 4 passengers, a full 10-passenger mini-van, or a bicycle-size vehicle for individual travel.

3. Focus first on service, then on technology. Light rail? Streetcar? Gondola? Hyperloop? The public consistently gets caught up in the latest sexy technology, but transit services must serve a need. We cannot chase technology as a solution in search of a problem. The foremost priority must be in creating a connected, accessible transit network that links major nodes, with limited time spent waiting and accessing service. The network should be designed first, linking origins and destinations that already exist or where growth is designated to occur. Then, terrain and existing conditions should inform decisions about what technology best fits the location.

4. Scientia potentia est, "knowledge is power." We live in an increasingly information intense society. This has impacted all sectors from news media to education. Public transportation services that have long existed (taxis, shuttles, car rentals) have been revolutionized by the availability of real-time information about vehicle location and driver ratings and ease of reservation and payment. Many transit agencies have used vehicle location data to inform customers in real time of transit arrival times, but implementing technology and data to improve services has been far too slow to allow transit to adequately compete.

All transit agencies should open up their real-time and schedule information to allow developers to create transit information tools; focus on keeping such data updated to make tools useful to the riding public; and push beyond real-time information into service disruption alerts and customer feedback mechanisms. The open data movement has been going strong in public transportation for about a decade, with recent advances through the Bureau of Transportation Statistics to encourage smaller agencies to follow suit (Bureau of Transportation Statistics 2017). A consortium of transit information providers has taken steps to outline best practices for General Transit Feed Specification (GTFS) data (General Transit Feed Specification 2017). However, without the push within transit agencies to keep such data updated according to best practices, rider information tools cannot exist or, in many cases, are providing false information to transit users. There must be a substantial effort within the agencies to communicate at the highest level with their riders to inform them about the status of service and obtain feedback.

\section{Will public transportation take the lead?}

In many ways, public transportation agencies have sat back to play it safe with taxpayers' money. The transit industry is filled with civil servants and equity advocates, not risk-takers. However, the resulting stifled innovation deters many of the concepts outlined above as public transportation is called upon to position itself for the future. The most livable and 
effective system includes public transportation not only in the role it serves today, but also as the backbone for high-capacity priority corridors that serve the bulk of trips attracting riders out of their single-occupancy vehicles. It is time for transit visionaries to take the lead to ensure that new technologies revolutionizing transportation are used to improve the livability and sustainability of communities. Collective mobility is the backbone of the future of transportation.

\section{References}

Bureau of Transportation Statistics. 2017. National Transit Map. Washington, DC: U.S. Department of Transportation. Retrieved from https://www.rita.dot.gov/bts/ntm/about

Chase, R. 2014. "Will a World of Driverless Cars Be Heaven or Hell?" CityLab, The Atlantic Monthly Group. Retrieved from https://www.citylab.com/transportation/2014/04/willworld-driverless-cars-be-heaven-or-hell/8784/

Davidson, L. 2017. "Will self-driving cars, taxis make mass transit obsolete?" The Salt Lake Tribune. Retrieved from http://www.sltrib.com/news/politics/2017/08/16/will-self-drivingcars-taxis-make-mass-transit-obsolete/

General Transit Feed Specification. 2017. Rocky Mountain Institute. http://gtfs.org/

Griggs, M. 2015. "Department of Transportation Says the Future of Transit Looks Pretty Bleak." Popular Science. Retrieved from http://www.popsci.com/new-dot-report-futuretransportation-looks-pretty-bleak

MaaS Global. 2017. Helsinki, Finland. http://maas.global/

Neff, J. and M. Dickens. 2017. 2016 Public Transportation Fact Book, 67th Edition. Washington, DC: American Public Transportation Association, Retrieved from http://www.apta.com/ resources/statistics/Documents/FactBook/2016-APTA-Fact-Book.pdf

Orcutt, J. 2016. Retrieved from https://twitter.com/jonorcutt

Polzin, S. 2016. Implications to Public Transportation of Emerging Technologies. National Center for Transit Research, University of South Florida. https://www.nctr.usf.edu/wp-content/ uploads/2016/11/Implications-for-Public-Transit-of-Emerging-Technologies-11-1-16.pdf

Richard, M. 2009. "Amount of Space Required to Transport People by Car, Bus, or Bicycle." Treehugger. Retrieved from https://www.treehugger.com/cars/amount-of-space-requiredto-transport-people-by-car-bus-or-bicycle.html

San Francisco County Transportation Authority. 2017. TNCs Today. https://www.sfmta.com/ sites/default/files/agendaitems/2017/6-20-17\%20Item\%2014\%20Transportation\%20 Network\%20Company\%20Actvity\%20Report.pdf

Sen, C. 2017. "What happens if Uber or Lyft outcompetes public transit?" Commentary. Chicago Tribune. Retrieved from http://www.chicagotribune.com/news/opinion/ commentary/ct-uber-lyft-public-transit-20170721-story.html

UbiGo. 2017. Gothenburg, Sweden. http://ubigo.se/ 
Vuchic, V. 2007. Urban Transit Systems and Technology. Hoboken, NJ: John Wiley \& Sons, Inc.

Wikibooks. 2017. Fundamentals of Transportation/Transit. Retrieved from https://en.wikibooks. org/wiki/Fundamentals_of_Transportation/Transit

\section{About the Author}

KARI Edison WATKINS, PH.D., P.E. (kari.watkins@ce.gatech.edu) is the Frederick Law Olmsted Associate Professor in Civil and Environmental Engineering at the Georgia Institute of Technology. Her primary interest is how technology and public space can be used to encourage active (biking, walking) and collective (transit, rideshare) transportation modes. Her teaching and research interests include multimodal transportation planning, the use of technology in transportation, traveler information, and complete streets design. She has made extensive inroads in public transportation leading OneBusAway, an award-winning open source app that provides transit information tools and assesses their impacts on riders. Prior to her doctoral studies, Dr. Watkins worked for a decade as a senior transportation engineer. 